\title{
Executive Dysfunction, Heart Disease Burden, and Remission of Geriatric Depression
}

\author{
George S Alexopoulos*,', Dimitris N Kiosses', Christopher Murphy' and Moonseong Heo' \\ 'Weill-Cornell Institute of Geriatric Psychiatry, Weill Medical College of Comell University, NY, USA
}

\begin{abstract}
This study investigated the relationship of executive impairment and heart disease burden to remission of major depression among elderly patients. A total of 112 elderly subjects suffering from major depression received treatment with citalopram at a target daily dose of $40 \mathrm{mg}$ for 8 weeks. Diagnosis was assigned using the Research Diagnostic Criteria and the DSM-IV Criteria after an interview with the Schedule for Affective Disorders and Schizophrenia. Executive dysfunction was assessed with the Initiation/Perseveration subscale of the Dementia Rating Scale (DRS) and the Color-Word Stroop test. Medical burden, including heart disease burden, was rated with the Cumulative Illness Rating Scale, and disability with Philadelphia Multilevel Instrument. Both abnormal initiation/perseveration and abnormal Stroop scores were associated with low remission rates of geriatric depression. Similarly, heart disease burden and baseline severity of depression also predicted low remission rates. The relationship of heart disease burden to remission was not mediated by executive dysfunction. Impairment in other DRS cognitive domains, disability, medical burden unrelated to heart disease did not significantly influence the outcome of depression in this sample. Executive dysfunction and heart disease burden constitute independent vulnerability factors that increase the risk for chronicity of geriatric depression. The findings of this study provide the rationale for investigation of the role of specific frontostriatal-limbic pathways in predisposing to geriatric depression or worsening its course. Neuropsychopharmacology (2004) 29, 2278-2284, advance online publication, I September 2004; doi: I 0. I038/sj.npp. I 300557
\end{abstract}

Keywords: depression; elderly; remission; executive impairment; heart disease burden

\section{INTRODUCTION}

Executive dysfunction, including disturbances in response inhibition and initiation as well as perseveration have been reported in late-life depression (Elderkin-Thompson et al, 2003; Lockwood et al, 2002; Nebes et al, 2001). Studies of cognitive response to psychopharmacological treatment of late-life depression indicate that executive function deficits persist after remission of geriatric depression (Nebes et al, 2003; Butters et al, 2000).

There is evidence that executive dysfunction and related neuropsychological abnormalities influence the course of depression. In a small number of young and middle-aged women, baseline executive dysfunction predicted poor response to fluoxetine (Dunkin et al, 2000). In elderly patients, impairment in frontal lobe tests (Trails B, card sorting perseveration) was associated with poor outcomes of geriatric depression (Simpson et al, 1998). Abnormal scores of initiation/perseveration appear to predict poor or delayed antidepressant response of

\footnotetext{
*Correspondence: Dr GS Alexopoulos, Weill-Cornell Institute of Geriatric Psychiatry, Weill Medical College of Cornell University, 21 Bloomingdale Road, White Plains, NY 10605, USA, Tel: + 1914997 5767, Fax: + I 914997 5826, E-mail: gsalexop@med.cornell.edu Received 29 December 2003; revised II March 2004; accepted 12 March 2004
}

geriatric major depression in patients treated with therapeutic dosages of various antidepressants over a period of 6 weeks (Kalayam and Alexopoulos, 1999). Moreover, abnormal initiation/perseveration scores are associated with early relapse and recurrence of geriatric major depression (Alexopoulos et al, 2000). These studies had methodological limitations, including uncontrolled treatment, short length of follow-up, infrequent follow-up assessments, and small number of subjects. Nonetheless, taken together, their findings suggest that executive dysfunction is associated with poor outcomes of geriatric depression.

Executive dysfunction, as a rule, results from impairment of frontostriatal pathways. Vascular disease has been thought to contribute to frontostriatal impairment in geriatric depression (Alexopoulos et al, 1997a; Krishnan et al, 1997). Patients with either evidence of peripheral vascular disease (Alexopoulos et al, 2002b, 1997b) or white matter hyperintensities (Krishnan et al, 1997) have impairment of executive functions, psychomotor retardation, reduced interest in activities, and limited insight, a clinical presentation suggestive of frontostriatal dysfunction. Moreover, white matter hyperintensities have been associated with poor outcomes of geriatric depression (Alexopoulos et al, 2002a; Steffens et al, 2001, Simpson et al, 1998; O'Brien et al, 1998; Hickie et al, 1997, 1995). 
This study focuses on the relationship of executive dysfunction to remission of geriatric major depression. Remission, defined as an almost asymptomatic state, is a critical clinical goal in the care of depression. Patients left with residual depressive symptoms have functional impairment, compromised quality of life, and high utilization of health care services (Lecrubier, 2002). Moreover, remission is a more stable clinical state with a lower risk for relapse than improvement of depression that leaves the patient with residual symptoms (Thase et al, 2001; Paykel et al, 1995; Mintz et al, 1992; Judd et al, 1996). While remission is desirable, clinical trials have shown that only a little over one-third of patients treated with commonly used antidepressants achieve remission (Thase et al, 2001).

Based on earlier literature, this study tested the hypothesis that executive dysfunction influences adversely the time to remission of elders with major depression receiving controlled treatment with citalopram. Assuming that cardiovascular disease contributes to frontostriatal impairment leading to executive dysfunction, the study further examined the impact of cardiovascular risk factors on time to remission.

\section{MATERIALS AND METHODS}

\section{Subjects}

The subjects were consecutively recruited elderly psychiatric patients aged 62 years and older, who agreed to participate in the study and signed informed consent. At entry, the subjects had met Research Diagnostic Criteria (Spitzer et al, 1978) and DSM-IV criteria (APA, 1994) for unipolar major depression without psychotic features, had a score of 17 or greater on the 24-item Hamilton Depression Rating Scale (HAM-D) (Hamilton, 1960), and a score of 1 (absent) on the Delusions and Hallucinations items of the Schedule for Affective Disorders and Schizophrenia-Lifetime version (SADS-L) (Spitzer and Endicott, 1975). The subjects were considered in remission if they no longer met DSM-IV criteria for depression and achieved an HAM-D below 10 .

Depressed patients were excluded if they had: (1) history of other psychiatric disorders (except personality disorders) prior to their depression; (2) severe or acute medical illness, that is, metastatic cancer, brain tumors, decompensated cardiac, hepatic or renal failure, or myocardial infarction, or stroke within the 3 months preceding the study; (3) neurological disorders, that is, delirium, history of head trauma, Parkinson's disease, and multiple sclerosis; (4) conditions and drugs that may cause depression, that is, endocrinopathies other than diabetes, lymphoma, pancreatic cancer, steroids, $\beta$-blockers, $\alpha$-methyl-dopa, clonidine, reserpine, tamoxifen, and cimetidine; and (5) Mini-Mental State Examination (MMSE) (Folstein et al, 1975) score $<24$. Therefore, the subjects were nondelusional depressed elderly patients without diagnosable dementia.

To increase adherence, only subjects residing within a 45min drive from the hospital were selected. All subjects were required to have informants who had knowledge of the subject's history and enough contact so that they could observe changes within a week.

\section{Measures}

The SADS-L and parts of the SCID-R (Spitzer and Williams, 1995) were initially administered when the subjects were symptomatic. Depressive symptoms were assessed using the 24-item HAM-D. Testing of this study's hypotheses relied exclusively on two measures of cognitive dysfunction, the Mattis Dementia Rating Scale (DRS) (Mattis, 1989) and the Stroop Color-Word (Golden, 1978) response inhibition test. The DRS yields subscores for impairment in: (1) initiation and perseveration (IP); (2) memory; (3) construction; (4) conceptualization, and (5) attention as well as a score of overall cognitive impairment. The IP domain tests: (1) verbal initiation/perseveration, for example, over $1 \mathrm{~min}$ name all things that you can buy in a supermarket; (2) alternating movements; and (3) graphomotor design, for example, reproduce XOXO. The Stroop Color-Word response inhibition test consists of presentation of equal number of the words 'red', 'blue', and 'green' printed in a congruent or incongruent ink color. Subjects were instructed to identify the ink color of each word.

At baseline, medical burden was assessed with the Cumulative Illness Rating Scale, modified version for geriatrics (CIRS-G) (Miller et al, 1992). The CIRS-G rates chronic medical burden from 14 organ-systems. Information was obtained from medical history, physical examination, as well as the available laboratory tests. A total score was computed by adding the subscores of each organ system except the psychiatric/behavioral system. Baseline disability was assessed with the Philadelphia Multilevel Assessment Instrument (Lawton et al, 1982).

\section{Study Procedures}

After baseline evaluation, the subjects were started on citalopram $20 \mathrm{mg}$ daily and the dosage was increased by $10 \mathrm{mg}$ to a target daily dose of $40 \mathrm{mg}$. Citalopram was administered in a single dose at bedtime. Subjects who developed insomnia receive citalopram in the morning. Citalopram was chosen because of its known efficacy in the treatment of geriatric depression and its limited drug interactions (Bezchlibnyk-Butler et al, 2000). The subjects received their medication in 1-week supply blisters that permitted dispensation of their daily dosage separately. Throughout the study, the patient visits followed a medication clinic model. No subject received psychotherapy.

The subjects were systematically assessed during the study on 2, 4, 6, and 8 weeks. Assessment consisted of administration of the HAM-D as well as pill counts.

\section{Data Analysis}

Bivariate comparisons among baseline variables were conducted using $\chi^{2}$ and the Wilcoxon-Mann-Whitney test. The relationships of measures of executive dysfunction (IP and Stroop) to time to remission were assessed with Cox's proportional hazards survival analysis. In these models, education was used as a covariate because it may influence performance in tasks of executive function. Other covariates were age and severity of depression (HAM-D) because subjects who achieved remission were younger and less 
depressed at baseline compared to subjects who remained depressed (Table 1). A similar approach was followed to study the relationship of heart disease burden to time to remission. Finally, models consisting of measures of executive dysfunction and heart disease burden along with covariates (education, age, and severity of depression) were constructed in order to examine whether executive dysfunction accounted for the relationship between heart disease burden and remission. Two-tailed significance is reported.

\section{RESULTS}

A total of 112 subjects entered the study. They were aged $62-92$ years $($ mean $=73.17, \mathrm{SD}=6.50)$ and the female to male ratio was 1.07:1. The average maximum dose of citalopram was $35.29 \mathrm{mg}$. By the 8th week of treatment, 96 subjects remained in the study and 16 subjects exited earlier than 8 weeks. There were no significant differences in age, baseline severity of depression (HAM-D), or cognitive impairment (DRS) between the subjects who reached the 8th week of the study and those who exited earlier.

Of the 112 subjects, 61 met criteria for remission (HAM$\mathrm{D}<10$ ), 35 completed the 8 -week study but did not meet criteria for remission, and 16 exited the study while still remaining depressed. Patients, who failed to achieve remission were older, had slightly more severe depression at baseline and greater overall cognitive impairment evidenced by lower total DRS scores (Table 1). However, the difference in cognitive impairment was accounted by lower scores in DRS IP subscores (Table 1). Unremitted subjects also had lower (abnormal) Stroop Color-Word scores. Subjects who failed to achieve remission had greater overall medical burden (CIRS-G) and higher heart disease burden (CIRS Heart Disease score), but vascular disease burden was not associated with remission; the higher overall medical burden was accounted by higher heart disease burden (Table 1). There were no differences in education, between remitted and unremitted subjects (Table 1).

Table I Demographic and Clinical Data in I 12 Elderly Patients with Major Depression Who Underwent Treatment with Citalopram Over a Period of 8 Weeks

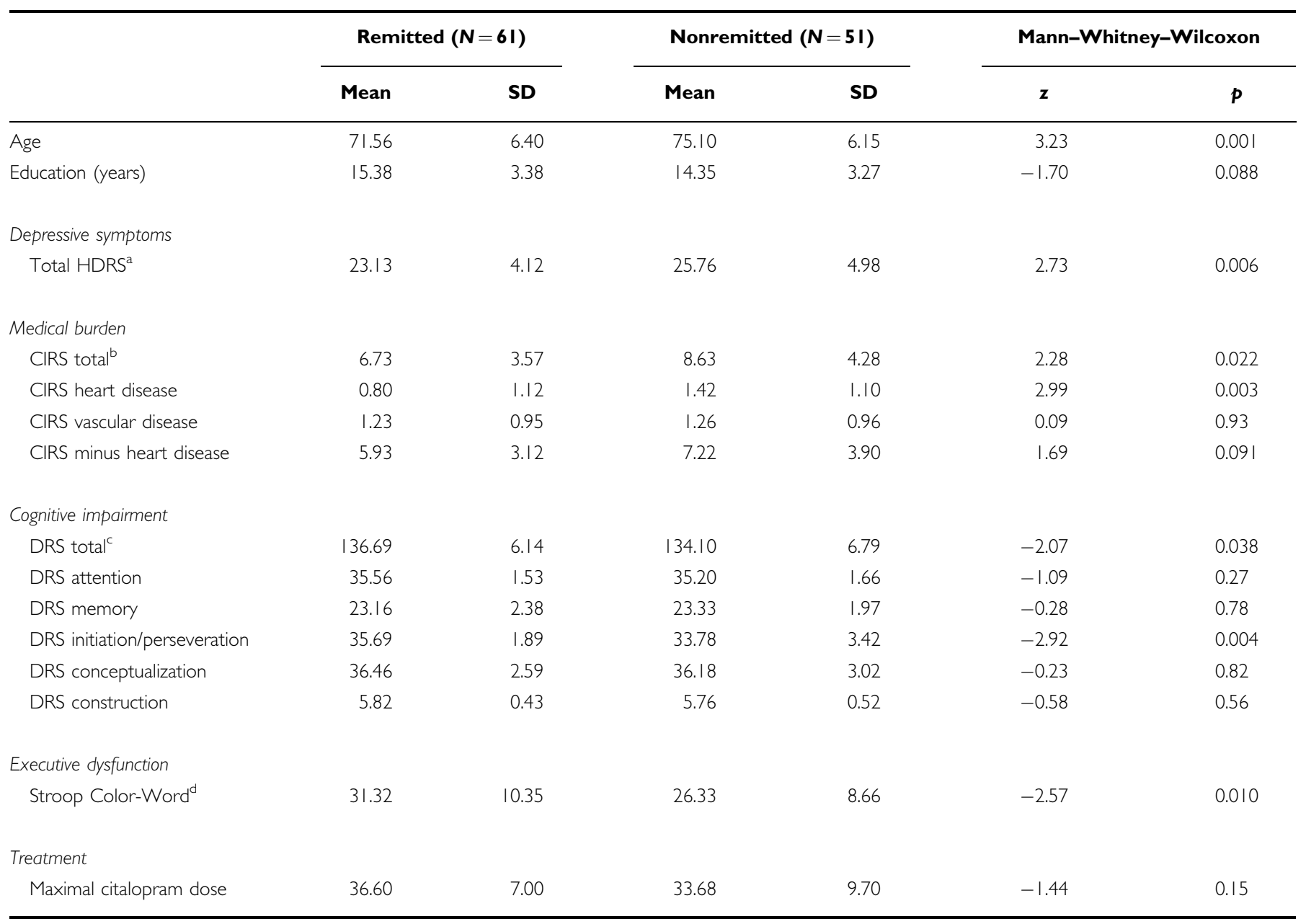

a24-item Hamilton Depression Rating Scale.

${ }^{\mathrm{b}}$ Cumulative Illness Rating Scale-Geriatric Version.

cMattis Dementia Rating Scale.

${ }^{\mathrm{d}}$ Stroop Response Inhibition Test: number of correct responses over $45 \mathrm{~s}$ during the response inhibition condition. 


\section{Time to Remission}

Cox's proportional hazards survival analysis demonstrated that low baseline IP scores were associated with longer time to remission and poor remission rate after taking into consideration the effect of education, age, and severity of depression (Table 2, Figure 1). Similarly, CIRS Heart Disease scores predicted poor remission rate after controlling for education, age, and severity of depression. IP scores were not significantly associated with CIRS Heart Disease scores when education, age, and HAM-D were used as covariates (partial $r_{\mathrm{s}}=-0.13, p=0.22$ ). When both IP and CIRS Heart Disease scores were entered in the same model, each remained associated with poor remission rates (Table 2), suggesting that the effect of CIRS Heart Disease scores on remission is not mediated by abnormal IP function. Medical burden resulting from conditions other than heart diseases (CIRS total minus Heart Disease) (Hazard ratio $(95 \% \quad \mathrm{CI})=0.95 \quad(0.89-1.02), \chi^{2}=1.80$, $\mathrm{df}=1, p=0.18)$ and IADL (Hazard ratio $(95 \% \mathrm{CI})=1.04$ $\left.(0.87-1.24), \chi^{2}=0.16, \mathrm{df}=1, p=0.69\right)$ were not significantly associated with remission in models using education, age, and severity of depression as covariates.

Examination of the relationship of baseline Stroop ColorWord scores to remission using partial residual plots showed that the relationship was linear for Stroop scores greater than 22 but not for lower scores. For this reason,

Table 2 Initiation Perseveration and Heart Disease Burden: Relationship to Remission in 112 Elderly Patients with Major Depression Treated with Citalopram

\begin{tabular}{|c|c|c|c|}
\hline Variables & Hazard ratio $(95 \% \mathrm{Cl})$ & Likelihood ratio $\chi^{2}$ & $p^{*}$ \\
\hline \multicolumn{4}{|l|}{ Model $A^{a}$} \\
\hline Age & $0.95(0.91-0.99)$ & 5.90 & 0.030 \\
\hline Education & I.0I $(0.93-1.10)$ & 0.10 & $>0.99$ \\
\hline HAM-D & $0.92(0.87-0.98)$ & 7.17 & 0.014 \\
\hline DRS IP & $1.18(1.04-1.33)$ & 7.03 & 0.016 \\
\hline \multicolumn{4}{|l|}{ Model $B^{c}$} \\
\hline Age & $0.95(0.91-0.99)$ & 4.70 & 0.060 \\
\hline Education & $1.05(0.96-1.14)$ & 1.19 & 0.548 \\
\hline HAM-D & $0.92(0.86-0.98)$ & 7.08 & 0.016 \\
\hline CIRS Heart $^{d}$ & $0.69(0.53-0.9 \mid)$ & 6.78 & 0.018 \\
\hline \multicolumn{4}{|l|}{ Model $C^{e}$} \\
\hline Age & $0.96(0.92-1.01)$ & 2.58 & 0.216 \\
\hline Education & $1.03(0.95-1.12)$ & 0.56 & $>0.99$ \\
\hline HAM-D & $0.92(0.86-0.98)$ & 6.88 & 0.018 \\
\hline CIRS Heart & $0.73(0.56-0.96)$ & 5.27 & 0.044 \\
\hline DRS IP & $1.16(1.03-1.32)$ & 5.55 & 0.036 \\
\hline \multicolumn{4}{|c|}{$\begin{array}{l}\text { *Bonferonni corrected } p \text {-values for two comparisons using DRS IP and Stroop } \\
\text { for modeling of remission. } \\
\text { aProportional hazards likelihood ratio } \chi^{2}=27.12, \mathrm{df}=4, p<0.000 \mathrm{I} \text {. } \\
\text { bMattis Dementia Rating Scale-Initiation/Perseveration domain. } \\
\text { 'Proportional hazards likelihood ratio } \chi^{2}=25.78, \mathrm{df}=4, p<0.000 \text { I. } \\
{ }^{\mathrm{d} C} \text { Cumulative Illness Rating Scale-Geriatric Version, Heart Disease Domain. } \\
\text { eProportional hazards likelihood ratio } \chi^{2}=31.34, \mathrm{df}=5, p<0.000 \text { I. }\end{array}$} \\
\hline
\end{tabular}

Stroop Color-Word scores of 22 or less were windsorized to 22. Cox's Proportional Hazards survival analysis showed that abnormal Stroop scores were associated with poor remission rate (Table 3). The hazard ratio of Stroop scores was not proportional over time as shown by the significant Stroop $\times$ time interaction (Table 3, Figure 2).

Heart disease burden was associated with poor remission rates (Table 2). However, heart disease burden was not

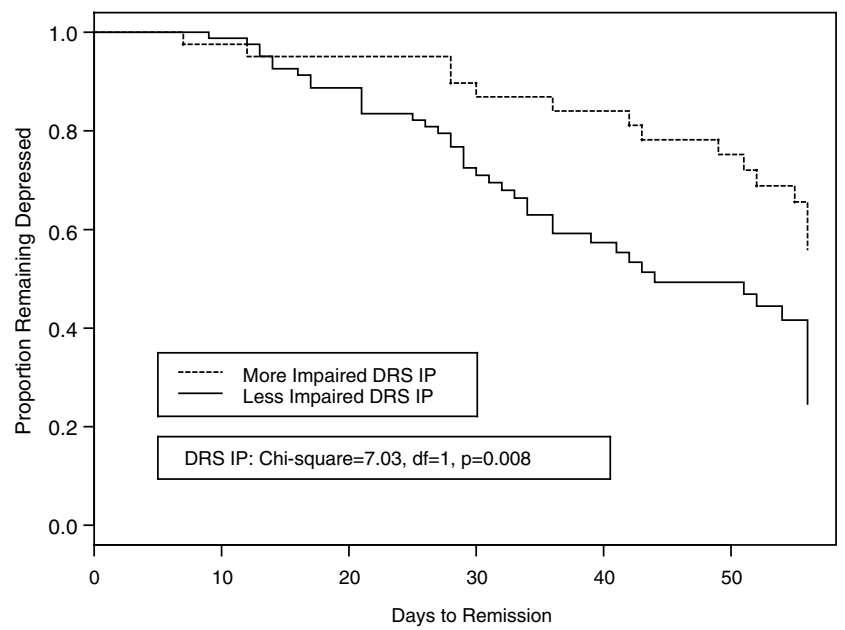

Figure I Remission rates in 112 elderly patients with major depression with high and low scores (median split) at the Dementia Rating Scale Initiation/Perseveration Domain (DRS IP). The DRS IP $\chi^{2}$ was estimated after adjustment for age, education, and severity of depression (HAM-D).

Table 3 Response Inhibition Function and Heart Disease Burden: Relationship to Remission in 112 Elderly Patients with Major Depression Treated with Citalopram

\begin{tabular}{|c|c|c|c|}
\hline Variables & Hazard ratio $(95 \% \mathrm{Cl})$ & Likelihood ratio $\chi^{2}$ & $p^{*}$ \\
\hline \multicolumn{4}{|l|}{ Model $A^{a}$} \\
\hline Age & $0.93(0.88-0.99)$ & 4.94 & 0.052 \\
\hline Education & $1.04(0.95-1.14)$ & 0.66 & 0.836 \\
\hline HAM-D ${ }^{b}$ & $0.92(0.86-0.98)$ & 6.46 & 0.022 \\
\hline Stroop ${ }^{c}$ & $1.02(0.97-1.07)$ & 0.51 & $>0.99$ \\
\hline Stroop $\times$ time $^{d}$ & $1.09(1.02-1.16)$ & 5.90 & 0.030 \\
\hline \multicolumn{4}{|l|}{ Model $B^{\mathrm{e}}$} \\
\hline Age & $0.95(0.89-1.00)$ & 3.31 & 0.138 \\
\hline Education & $1.07(0.97-1.18)$ & 1.70 & 0.386 \\
\hline HAM-D & $0.92(0.86-0.98)$ & 6.17 & 0.026 \\
\hline CIRS Heart ${ }^{f}$ & $0.69(0.5 \mid-0.93)$ & 6.14 & 0.026 \\
\hline Stroop & $1.01(0.96-1.06)$ & 0.08 & $>0.99$ \\
\hline Stroop $\times$ time & $1.08(1.01-1.16)$ & 5.32 & 0.042 \\
\hline
\end{tabular}

*Bonferonni corrected $p$-values for two comparisons using DRS IP and Stroop for modeling of remission.

aProportional hazards likelihood ratio $\chi^{2}=24.64, \mathrm{df}=5, p=0.0002$

b24-item Hamilton Depression Rating Scale.

'Stroop Color-Word scores.

${ }^{\mathrm{d}}$ Time $=\log$ (time to remission) -3.54 ; The constant, 3.54, is the average of the logs of the survival times.

eProportional hazards likelihood ratio $\chi^{2}=29.80, \mathrm{df}=6, p<0.000$ I

${ }^{\mathrm{f} C}$ Cumulative Illness Rating Scale-Geriatric Version, Heart Disease Domain. 


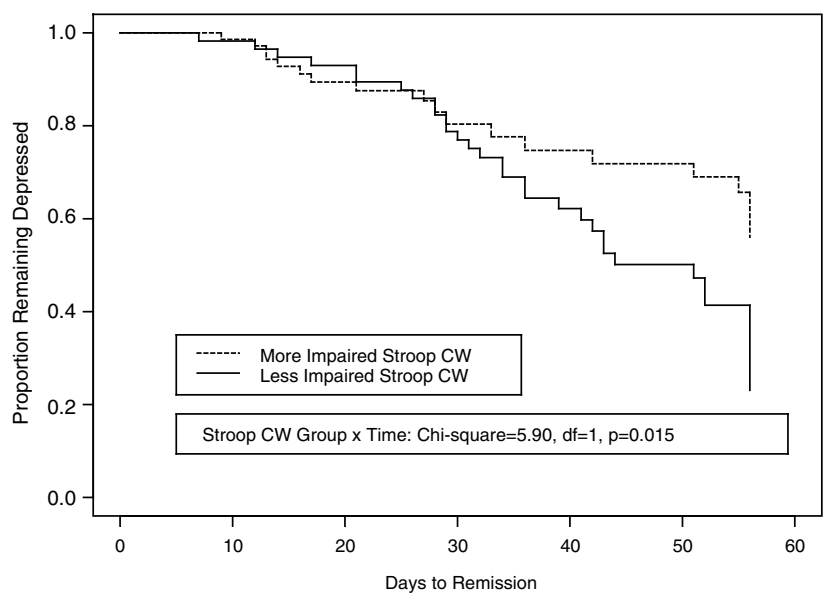

Figure 2 Remission rates in 112 elderly patients with major depression with high and low scores (Median Split) at the Stroop Color-Word Test. The Stroop Color-Word $\chi^{2}$ was estimated after adjustment for age, education, and severity of depression (HAM-D).

significantly correlated with response inhibition when education, age, and HAM-D were taken into consideration (Stroop scores partial $r_{\mathrm{s}}=-0.14, p=0.17$ ). Introducing both Stroop and CIRS Heart Disease scores in the same model demonstrated that each was associated with poor remission rate, suggesting that the effect of CIRS Heart Disease scores on remission is not mediated by abnormal response inhibition functions assessed by the Stroop test.

\section{DISCUSSION}

The principal finding of this study is that abnormal scores in IP, or response inhibition tasks are associated with poorer remission rate of geriatric depression. Cardiac disease burden was also associated with poor remission rate, but the effect of cardiac burden on remission was not mediated by impairment in either IP or response inhibition.

To our knowledge, this is the first controlled study to demonstrate a relationship between abnormal executive functions, remission, and symptom improvement of geriatric depression after treatment with a single antidepressant. This finding is consistent with earlier observations of uncontrolled treatment studies, which observed that impairment in some executive functions predict adverse outcomes of geriatric depression (Simpson et al, 1998; Kalayam and Alexopoulos, 1999; Alexopoulos et al, 2000).

The frequent co-occurrence of executive dysfunction and late-life depression as well as the relationship of executive dysfunction to the course of depression suggest that common or related abnormalities predispose to both depressive symptoms and executive dysfunction. Clinical, structural neuroimaging, and brain function studies suggest that frontostriatal-limbic dysfunction is a candidate abnormality (Alexopoulos, 2002). Neurological disorders leading to executive dysfunction, including Parkinson's disease, supranuclear palsy, and Huntington's disease, are often complicated by depression and accompanied by executive dysfunction (Sobin and Sackeim, 1997). Consistent with clinical observations, MRI studies have shown that hyperintensities are common in subcortical structures and their frontal and limbic connections of depressed elders with executive dysfunction (Krishnan et al, 1997). Ischemic lesions of the caudate head and the left frontal pole often lead to depression (Starkstein et al, 1988). Abnormal metabolism of the caudate nucleus and the frontal regions have also been observed in depression (Drevets, 2000). Depressed elderly patients have reduced activation of the dorsal anterior cingulate after a paced word activation task compared to normal elders (de Asis et al, 2001). The basal ganglia, the prefrontal areas, the amygdala, and some paralimbic regions appear to be abnormally activated in young depressives (Drevets, 1998).

Along with this study's findings, emerging evidence suggests that frontostriatal-limbic abnormalities are associated with poor outcomes of depression. White matter hyperintensities have been associated both with executive dysfunction (Aizenstein et al, 2002; Boone et al, 1992) and with poor outcomes of geriatric depression (Hickie et al, 1995, 1997; Simpson et al, 1998; O'Brien et al, 1998; Steffens et al, 2001). Hypometabolism of the rostral anterior cingulate was reported in treatment-resistant depression, while cingulate hypermetabolism was associated with favorable response (Mayberg, 1997; Mayberg et al, 1997); integrity of the anterior cingulate is required for the executive functions tested by the IP and the Stroop. An electrical tomography analysis study suggests that anterior cingulate activity is a predictor of the extent of treatment response in depressed younger adults (Pizzagalli et al, 2001); functional integrity of the anterior cingulated cortex is required for the performance of executive functions. Finally, an electrophysiological study demonstrated that increased left frontal error negative wave amplitude following Stroop activation predicts limited or slow change in depressive symptoms in elders receiving citalopram treatment (Kalayam and Alexopoulos, 2003).

From the theoretical point of view, this study's findings suggest that disruption in frontostriatal-limbic pathways underlying executive dysfunction confers a morbid vulnerability that increases the propensity of geriatric depression towards chronicity. Conceptualizing executive dysfunction as a vulnerability factor allows that clinical, for example, noncardiac medical burden or disability, may modify the impact of vulnerability resulting from frontostriatal-limbic impairment, although no such effects were observed in this sample.

Dysfunction of frontostriatal-limbic pathways can occur through a variety of mechanisms, including vascular and degenerative processes that may disrupt this circuitry directly or by damaging its connections to monoaminergic stem nuclei (Alexopoulos, 2002; Mayberg and Solomon, 1995; Krishnan, 1993). Nonetheless, in this study, there was no relationship between vascular disease burden and remission of geriatric depression. Moreover, heart disease burden was associated with poor remission rates, but its effect was not mediated by executive dysfunction. These observations do not support the part of the 'vascular depression' hypothesis, which postulates that vascular changes leading to frontostriatal dysfunction perpetuate late-life depression (Alexopoulos et al, 1997a). An alternative explanation is that the global measures of vascular and heart disease burden used in this study are inadequate for assessing the integrity of cerebral vasculature. 
Executive dysfunction and related behavioral abnormalities may have been misidentified as depressive symptoms, thus leading to an inflated number of nonremitted patients among those with executive dysfunction. However, use of a rather liberal definition of remission $(\mathrm{HAM}-\mathrm{D}<10)$ may have reduced the impact of this potentially confounding factor. Another potential shortcoming of this study is the limited assessment of executive functions. However, the DRS IP and the Stroop tests administered in this study have been associated with frontostriatal function in clinical and functional neuroimaging studies. Autopsy studies have shown that patients with the subcortical dementing disorders perform worse than patients with cortical dementia on the IP subscale of the DRS (Rosser and Hodges, 1994). Similarly, impairment in the IP subscale of the DRS and limited impairment in the DRS memory subscale characterized patients with Parkinson's disease and distinguished them from Alzheimer's patients (Paolo et al, 1995). In addition, functional neuroimaging studies suggest that functions tested by the IP subscale require integrity of prefrontal circuitry. Performance of a verbal fluency task was shown to result in increased left dorsolateral prefrontal activity (Frith et al, 1991). Learning of a new motor sequence is associated with activation of the dorsolateral cortex and the anterior cingulate (Hikosaka et al, 1998; Jueptner et al, 1997). Finally, response inhibition tasks, like those of the Stroop test, lead to activation of the anterior cingulate cortex (Bush et al, 2000; Davidson et al, 2002). Nevertheless, replication of this study with a more detailed executive dysfunction assessment is necessary.

In conclusion, this study documents that executive dysfunction and heart disease burden constitute independent vulnerability factors that increase the risk for chronicity of geriatric depression. The heuristic value of this finding is that it provides the basis for empirical investigation of the role of specific frontostriatal-limbic pathways in modifying the course of geriatric depression.

\section{ACKNOWLEDGEMENTS}

This work was supported by NIMH Grants RO1 MH65653, RO1 MH42819, RO1 MH51842, P30 MH68638, Forest Pharmaceuticals, the Sanchez Foundation, and Dr I Foundation (Dr Alexopoulos).

\section{REFERENCES}

Aizenstein HJ, Nebes RD, Meltzer CC, Fukui MB, Williams RL, Saxton J et al (2002). The relation of white matter hyperintensities to implicit learning in healthy older adults. Int J Geriatr Psychiatry 17: 664-669.

Alexopoulos GS (2002). Frontostriatal and limbic dysfunction in late-life depression. Am J Geriatr Psychiatry 10: 687-695.

Alexopoulos GS, Kiosses DN, Choi SJ, Murphy CF, Lim KO (2002a). Frontal white matter microstructure and treatment response of late-life depression: a preliminary study. Am J Psychiatry 159: 1929-1932.

Alexopoulos GS, Kiosses DN, Klimstra S, Kalayam B, Bruce ML (2002b). Clinical presentation of the 'depression-executive dysfunction syndrome of late life. Am J Geriatr Psychiatry 10: 98-102.
Alexopoulos GS, Meyers BS, Young RC, Campbell S, Sibersweig D, Charlson M (1997a). The 'vascular depression' hypothesis. Arch Gen Psychiatry 54: 915-922.

Alexopoulos GS, Meyers BS, Young RC, Kakuma T, Silbersweig D, Charlson M (1997b). Clinically defined vascular depression. Am J Psychiatry 154: 562-565.

Alexopoulos GS, Meyers BS, Young RC, Kalayam B, Kakuma T, Gabriele $\mathrm{M}$ et al (2000). Executive dysfunction and long-term outcomes of geriatric depression. Arch Gen Psychiatry 57: 285-290.

American Psychiatric Association. Committee on Nomenclature and Statistics (1994). Diagnostic and Statistical Manual of Mental Disorders, 4th edn. (DSM-IV) American Psychiatric Association: Washington, DC.

Bezchlibnyk-Butler K, Aleksic I, Kennedy SH (2000). Citalopram. A review of pharmacological and clinical effects. J Psychiatry Neurosci 25: 241-254.

Boone KB, Miller BL, Lesser IM, Merhinger CM, Hill-Gutierrez E, Goldberg $M$ et al (1992). Neuropsychological correlates of white matter lesions in healthy elderly subjects. Arch Neurol 49: 549-554.

Bush G, Luu P, Posner MI (2000). Cognitive and emotional influences in anterior cingulate cortex. Trends Cogn Sci 4: 215-222.

Butters MA, Becker JT, Nebes RD, Zmuda MD, Mulsant BH, Pollock BG et al (2000). Changes in cognitive functioning following treatment of late-life depression. Am J Psychiatry 157: 1949-1954.

Davidson RJ, Pizzagalli D, Nitschke JB, Putnam K (2002). Depression: perspectives from affective neuroscience. Annu Rev Psychol 53: 545-574.

de Asis JM, Stern E, Alexopoulos GS, Pan H, Gorp WV, Blumberg $\mathrm{H}$ et al (2001). Hippocampal and anterior cingulate activation deficits in patients with geriatric depression. Am J Psychiatry 158: 1321-1323.

Drevets WC (1998). Functional neuroimaging studies of depression: the anatomy of melancholia. Annu Rev Med 49: 341-361.

Drevets WC (2000). Neuroimaging studies of mood disorders. Biol Psychiatry 48: 813-819.

Dunkin JJ, Leuchter AF, Cook IA, Kasl-Godley JE, Abrams M, Rosenberg-Thompson S (2000). Executive dysfunction predicts nonresponse to fluoxetine in major depression. J Affect Disord 60: $13-23$.

Elderkin-Thompson V, Kumar A, Bilker WB, Dunkin JJ, Mintz J, Moberg PJ et al (2003). Neuropsychological deficits among patients with late-onset minor and major depression. Arch Clin Neuropsychol 18: 529-549.

Folstein MF, Folstein SE, McHugh PR (1975). 'Mini-mental state'. J Psychiatric Res 12: 189-198.

Frith CD, Friston KJ, Liddle PF, Frackowiak RSJ (1991). A PET study of word finding. Neuropsychologia 12: 1137-1148.

Golden CJ (1978). The Stroop Color and Word Test (Manual). Stoetling: Chicago.

Hamilton M (1960). A rating scale for depression. J Neurol Neurosurg Psychiatry 23: 56-62.

Hickie I, Scott E, Mitchell P, Wilhelm K, Austin MP, Bennett B (1995). Subcortical hyperintensities on magnetic resonance imaging: clinical correlates and prognostic significance in patients with severe depression. Biol Psychiatry 37: 151-160.

Hickie I, Scott E, Wilhelm K, Brodaty H (1997). Subcortical hyperintensities on magnetic resonance imaging in patients with severe depression - a longitudinal evaluation. Biol Psychiatry 42: 367-374.

Hikosaka SK, Miyauchi S, Takino R, Sasaki Y, Putz B (1998). Transition of brain activation from frontal to parietal areas in visuomotor sequence learning. J Neurosci 18: 1827-1840.

Judd LL, Akiskal HS, Maser JD, Zeller PJ, Endicott J, Coryell W et al (1996). Major depressive disorder: a prospective study of 
residual subthreshold depressive symptoms as predictor of rapid relapse. J Affect Disord 50: 97-108.

Jueptner M, Stephan KM, Frith CD, Brooks DJ, Frackowiak RSJ, Passingham RE (1997). Anatomy of motor learning. I. Frontal cortex and attention to action. J Neurophysiol 77: 1313-1324.

Kalayam B, Alexopoulos G (1999). Prefrontal dysfunction and treatment response in geriatric depression. Arch Gen Psychiatry 56: 713-718.

Kalayam B, Alexopoulos GS (2003). Left frontal error negativity and symptom improvement in geriatric depression: a preliminary study. Am J Psychiatry 160: 2054-2056.

Krishnan KRR (1993). Neuroanatomic substrates of depression in the elderly. J Geriatr Psychiatry Neurol 1: 39-58.

Krishnan KRR, Hays JC, Blazer DG (1997). MRI-defined vascular depression. Am J Psychiatry 154: 497-500.

Lawton MP, Moss M, Fulcomer M, Kleban MH (1982). A research and services oriented Multilevel Assessment Instrument. J Gerontol 37: 91-99.

Lecrubier Y (2002). How do you define remission? Acta Psychiatr Scand Suppl 415: 7-11.

Lockwood CA, Alexopoulos GS, van Gorp WG (2002). Executive dysfunction in geriatric depression. Am J Psychiatry 159: $1119-1126$.

Mattis S (1989). Dementia Rating Scale. Psychological Assessment Resources: Odessa, FL.

Mayberg HS (1997). Limbic-cortical dysregulation. A proposed model of depression. J Neuropsychiatry Clin Neurosci 9: 471-481.

Mayberg HS, Brannan SK, Mahurin RK, Jerabek PA, Brickman JS, Tekell JL et al (1997). Cingulate function in depression: a potential predictor of treatment response. NeuroReport 8: 1057-1061.

Mayberg HS, Solomon DH (1995). Depression in Parkinson's disease: a biochemical and organic viewpoint, in behavioral neurology of movement disorders. In: Weiner WJ, Lang AE (eds). Advances in Neurology, Vol. 65. Raven Press: New York. pp 49-60.

Miller MD, Paradis CF, Houck PR, Mazumdar S, Stack JA, Rifai AH et al (1992). Rating chronic medical burden in geropsychiatric practice and research: application on the Cumulative Illness Rating Scale. Psychiatry Res 41: 237-248.

Mintz J, Mintz LI, Arruda MJ, Hwang SS (1992). Treatments of depression and the functional capacity to work. Arch Gen Psychiatry 49: 761-768.

Nebes RD, Butters MA, Houck PR, Zmuda MD, Aizenstein H, Pollock BG et al (2001). Dual-task performance in depressed geriatric patients. Psychiatry Res 102: 139-151.
Nebes RD, Pollock BG, Houck PR, Butters MA, Mulsant BH, Zmuda MD et al (2003). Persistence of cognitive impairment in geriatric patients following antidepressant treatment: a randomized, double-blind clinical trial with nortriptyline and paroxetine. J Psychiatr Res 37: 99-108.

O'Brien J, Ames D, Chiu E, Schweitzer I, Desmond P, Tress B (1998). Severe deep white matter lesions and outcome in elderly patients with major depressive disorder: follow-up study. BMJ 317: 982-984.

Paolo AM, Troster AI, Glatt SL, Hubble JP, Koller WC (1995). Differentiation of Alzheimer's and Parkinson's disease with the Dementia Rating Scale. J Geriatr Psychiatry Neurol 8: 184-188.

Paykel ES, Ramana R, Cooper Z, Hayhurst H, Kerr J, Barocka A (1995). Residual symptoms after partial remission: an important outcome in depression. Psychol Med 25: 1171-1180.

Pizzagalli D, Pascual-Marqui RD, Nitschke JB, Oakes TR, Larson CL, Abercrombie HC et al (2001). Anterior cingulate activity as a predictor of degree of treatment response in major depression: evidence from brain electrical tomography analysis. Am J Psychiatry 158: 405-415.

Rosser AF, Hodges JR (1994). The Dementia Rating Scale in Alzheimer's disease, Huntington's disease and progressive supranuclear palsy. J Neurol 241: 531-536.

Simpson S, Baldwin RC, Jackson A, Burns AS (1998). Is subcortical disease associated with poor response to antidepressants? Neurological, neuropsychological and neuroradiological findings in late-life depression. Psychol Med 28: 1015-1026.

Sobin C, Sackeim HA (1997). Psychomotor symptoms of depression. Am J Psychiatry 154: 4-17.

Spitzer R, Endicott J, Robins E (1978). Research diagnostic criteria. Arch Gen Psychiatry 35: 773-782.

Spitzer RL, Endicott J (1975). Schedule for Affective Disorders and Schizophrenia-Lifetime Version. Biometrics Research Department. New York State Psychiatric Institute: New York, NY.

Spitzer RL, Williams JBW (1995). Structured Clinical Interview for DSM-IV Patient Version. Biometrics Research Department. New York State Psychiatric Institute: New York.

Starkstein SE, Robinson RG, Berthier ML, Price TR (1988). Depressive disorders following posterior circulation as compared with middle cerebral artery infarcts. Brain 111: 375-387.

Steffens DC, Conway CR, Dombeck CB, Wagner HR, Tupler LA, Weiner RD (2001). Severity of subcortical gray matter hyperintensity predicts ECT response in geriatric depression. J ECT 158: 405-415.

Thase ME, Entsuah AR, Rudolph RL (2001). Remission rates during treatment with venlafaxine or selective serotonin reuptake inhibitors. Br J Psychiatry 178: 234-241. 